This item is the archived peer-reviewed author-version of:

We are connected : fleahost association networks in the plague outbreak focus in the Rift Valley, northern Tanzania

\title{
Reference:
}

Makundi Rhodes H., Massawe Apia W., Borremans Benny, Laudisoit Anne, Katakweba Abdul.- We are connected : fleahost association networks in the plague outbreak focus in the Rift Valley, northern Tanzania

Wildlife research - ISSN 1035-3712 - 42(2015), p. 196-206

DOI: http://dx.doi.org/doi:10.1071/WR14254 
1 This is a pre-publication version of the article for University of Antwerp archiving purposes.

2 The published, formatted version can be downloaded at:

3 http://www.publish.csiro.au/paper/WR14254.htm

$4 \quad$ or can be requested by emailing rmakundi@yahoo.com

7 We are connected: flea-host association networks in the plague outbreak focus in the Rift Valley, northern Tanzania

8 Rhodes H. MakundiA,D, Apia W. MassaweA, Benny BorremansB, Anne LaudisoitB,C and Abdul KatakwebaA

9 APest Management Centre, Sokoine University of Agriculture, PO Box 3110, Morogoro, 0505 TZ.MO.MU, Tanzania.

10 BEvolutionary Ecology Group, University of Antwerp,B-2020 Antwerpen, Belgium.

11 CInstitute of Integrative Biology, University of Liverpool, Liverpool, L69 7ZB, UK.

12 DCorresponding author Email: rmakundi@yahoo.com

13 Context. Plague is a serious health problem in northern Tanzania, with outbreaks since 2008 in two districts located in Rift Valley. There is dearth of

14 knowledge on diversity of small mammal and flea fauna occurring in this plague focus. Knowledge on interactions between fleas and rodent species that

15 harbour the plague bacterium, Yersinia pestis, is important for developing strategies for control and prevention of plague. 
Aims. This study aims to show how rodents and fleas are associated with each other in the plague focus.

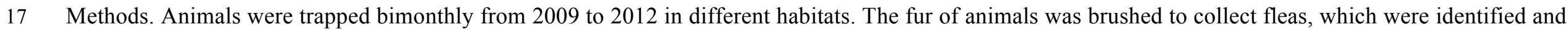
18 quantified. Network analysis methods, randomisation and rarefaction curves were used to show how hosts and fleas are associated.

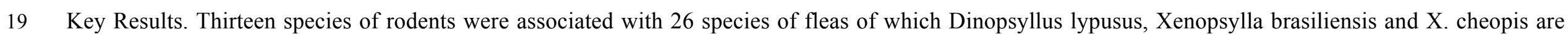

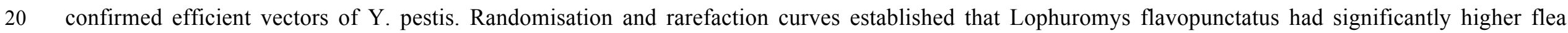

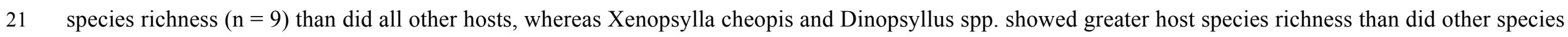

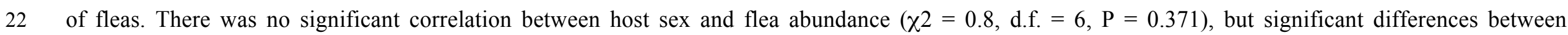

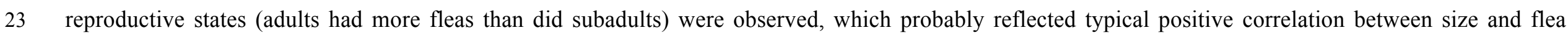
24 abundance $(\chi 2=4.1955$, d.f. $=1, \mathrm{P}=0.040)$.

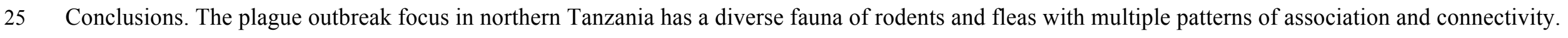

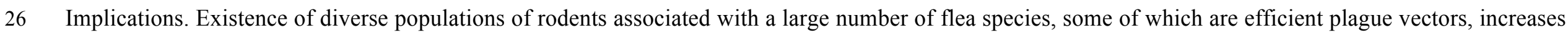

27 the potential for persistence and transmission of plague to humans in northern Tanzania.

28 WR14254

29 R. H. Makundi et al.

$30 \quad$ Flea-host association patterns in Tanzania

31 ToC Abstract 
Plague is a major health threat globally and in particular Africa where active foci have been reported in several countries including Madagascar, Democratic Republic of Congo, Tanzania and Uganda. Rodents are the main reservoir hosts from which the bacterium is transmitted to humans by fleas. The study in Tanzania shows complex association and interactions between rodents and fleas in various habitats including human settlements. Management of plague outbreaks should focus on reducing interactions between rodents, fleas and people to prevent infections.

Received 12 December 2014, accepted 10 May 2015

Additional keywords: Karatu, Mbulu, Yersinia pestis, rodents.

Introduction

Plague is a zoonotic disease, essentially of rodents, caused by the bacterium Yersinia pestis. It is primarily transmitted from infected rodents to humans by

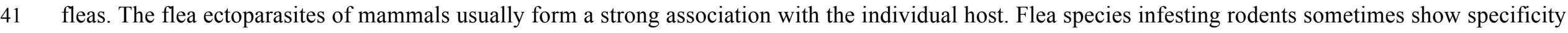

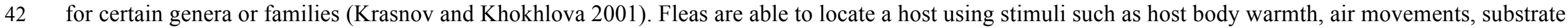

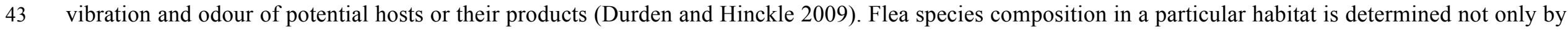

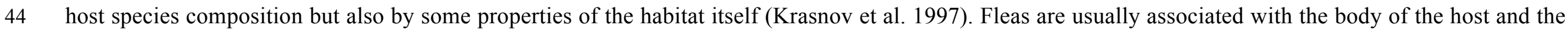

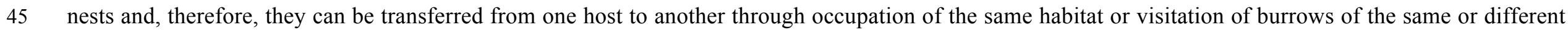

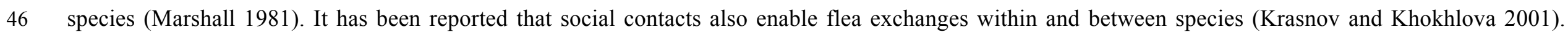

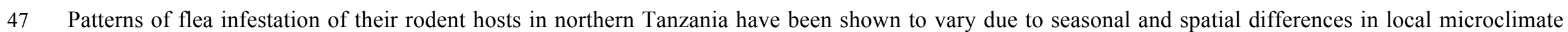

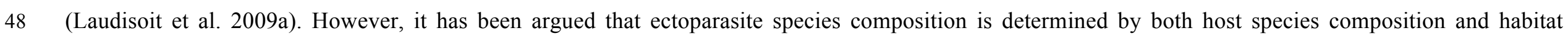


properties, but variations in flea species composition between localities in the tropics seem to be explained better by host species composition (Laudisoit et al. 2009b).

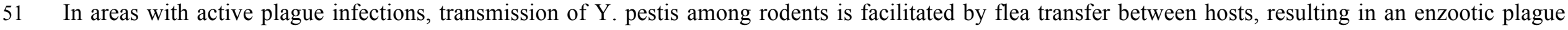

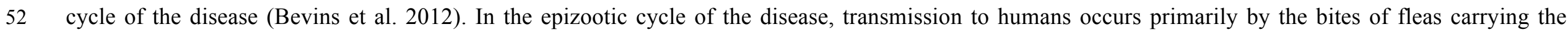

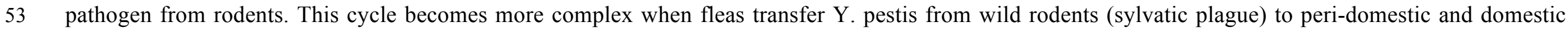

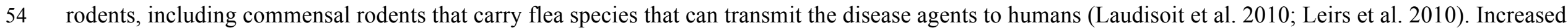

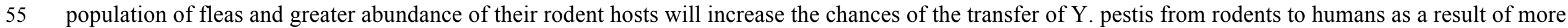

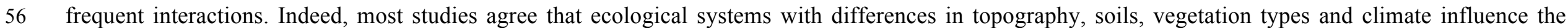
diversity of host species, resulting in differences in the species composition and abundance of flea communities (Durden and Hinckle 2009), which could thus determine the transmission and persistence of plague in an area (Gage and Kosoy 2005; Laudisoit et al. 2009a; Laudisoit et al. 2009b). Plague is enzootic in wild rodent populations in several localities in Tanzania (Kilonzo and Mtoi, 1983; Kilonzo et al. 2005). In recent studies, evidence of Y. pestis DNA in rodents in the plague active foci in Mbulu and Karatu districts in northern Tanzania was reported (Ziwa et al. 2013). Previous studies in the area have shown that several species of rodents were serologically positive for Y. pestis F1 antigen during plague outbreaks (Makundi et al. 2008). Unfortunately, studies regarding the diversity of fleas and their interaction with their rodent hosts, which may shed light on how plague spreads from wild rodents to humans, are largely inadequate. Previous studies in plague-endemic areas in Tanzania primarily provided taxonomic lists of hosts and their 
Mbulu District (Haule et al. 2013), but the study was based on a few hosts and flea species and the authors did not show how the ectoparasites were associated with different host species.

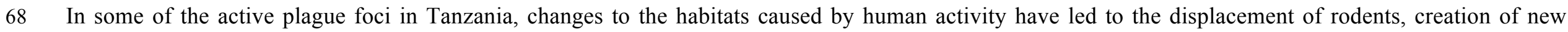

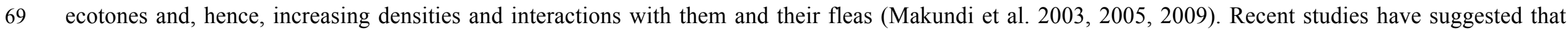

70 land use could affect the risk of local transmission of plague (McCauley et al. 2015).

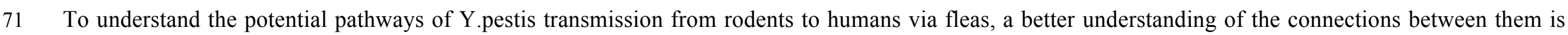

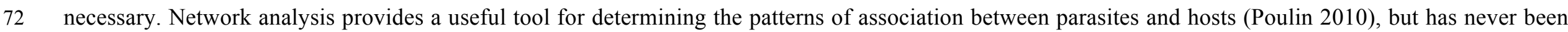

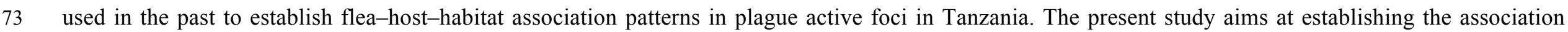
74 patterns of rodents and fleas in their natural habitats and potential effect in rodent plague dynamics.

75 Materials and methods

76 Study area

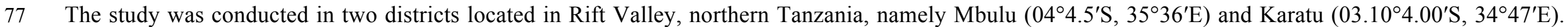

78 The study areas are inhabited by the same ethnic group, the Iraqw, a Cushitic-speaking people of Afro-Asiatic origin.

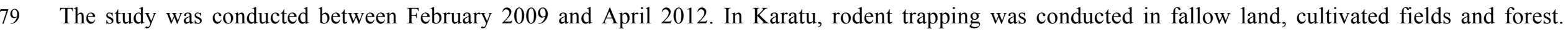

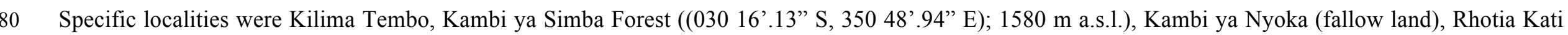

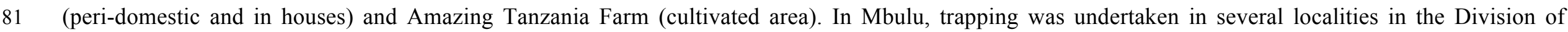

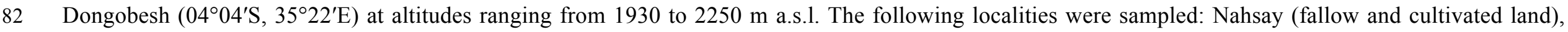


The moist forest habitat consisted of closed canopy of tall and medium-height trees of different species, with a dense undergrowth of herbaceous plants, liana of different species and shrubs.

Cultivated land consisted of farmland planted with maize (Zea mays) intercropped with common beans (Phaseolus vulgaris). The unweeded-farm notable vegetation was mainly herbs of different species. Common herbs in farmland included Amaranthus spinosum, Solanum incunum, Calylsea abyssinica, Coelina benghalensis and Sesa angolense.

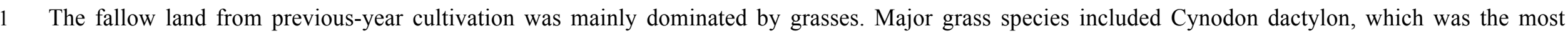

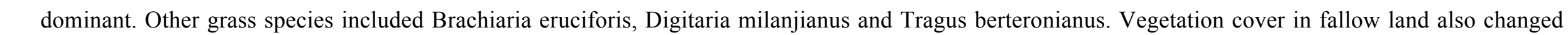
depending on the season (wet or dry) and the intensity of grazing by cattle, goats and sheep.

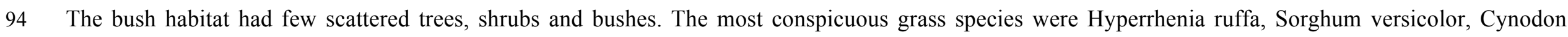

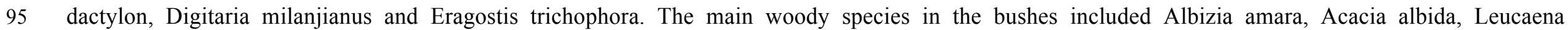

96 leucocephala, Acacia tortilis, A. xanthophloea and Sesbania bispinosa.

97 Peri-domestic areas were surroundings located 5-10 m from houses and were either cropped with maize and beans or were fallow during the study period.

98 The domestic environment consisted of the house and the immediate surroundings (0-5 m from the house), which were usually not cultivated. 
Animals were live-trapped bimonthly from February 2009 to April 2012. We used Sherman traps baited with peanut butter mixed with maize flour. In each of the study habitats, 100 traps were set in 10 trap lines, each consisting of 10 trapping stations $(10 \times 10) 10$ m apart for three consecutive nights and were checked every morning. In peri-domestic areas, the number of traps and how they were set depended on the configuration of the surroundings. Typically, we elsewhere (Laudisoit et al. 2009a). Identification of animals followed Kingdon's field guide for African mammals (Kingdon 1974).

Researchers observed and complied with laws, regulations and policies on humane care and handling of animals for research purposes guided by the Code of Conduct for Research Ethics of Sokoine University of Agriculture, Tanzania, and Tanzania's Animal Welfare Act of 2008.

Data from all trapping sessions were used for analyses. Because of logistical limitations, it was not possible to identify all fleas found on all rodents, and the

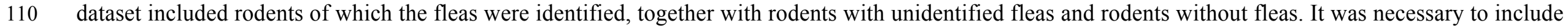

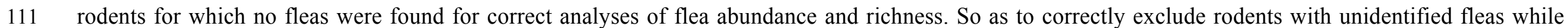
including rodents without fleas, we used the following method. First, we calculated the proportion of flea-positive rodents for which the fleas were identified. The same proportion of rodents on which no fleas were found was randomly chosen to be included in the final dataset.

\section{Network analysis}


We used network-analysis methods (Poulin 2010) to show in one graph how flea species and their hosts are associated. Every host and flea species was a point (node) in the graph, and for each flea that was observed on a host species, a connection (edge) was drawn between the two. Rodents without fleas were connected with 'no fleas' node. For each node, we indicated the proportion of habitats in which the corresponding species was found. For network analysis, habitats were grouped into the following three: domestic (sampled in domestic and peri-domestic habitats), field (cultivated land and fallow land) and forest (bush and forest).

We used a linear regression analysis to test whether the number of host individuals (log-transformed) caught correlated with the number of flea species found on the host species. A generalised linear mixed-effects model with log-link function (for Poisson distributed data) was used to test for correlations between richness or abundance and among habitat, reproductive age and sex, where these three variables were treated as random effects, and species was included as random effect to account for inter-species differences between sample size and habitat. We used a standard method involving randomisation and rarefaction, a statistical method to estimate and compare richness (Krebs 2009), that takes into account the sample size and calculates the rarefaction (or species accumulation) curves. The rarefaction curves estimated the expected number of species for a range of sample sizes, which was obtained by bootstrapping. For instance, if 90 Mastomys natalensis individuals had about nine flea species, then it would be possible to intrapolate how many flea species would be detected if only $10 \mathrm{M}$. natalensis individuals were sampled. To estimate this, 10 individuals were randomly chosen on which the number of flea species was counted. This step was repeated (1000 iterations), and the average number of species was taken, with $95 \%$ confidence interval. This was performed for the whole range of sample sizes between 1 and 116 individuals, which resulted into the rarefaction curve.

131 Two-by-two comparisons of flea species richness and host species richness 
We used the rarefaction data to compare the flea species richness of any two rodent host species. For each combination of host species, the minimum possible number of individuals was chosen, which was the maximum for the species with the least number of captured individuals (e.g. if Host species A had 10 individuals, and Host species B had 20, the rarefaction data were used for 10 individuals for both species). By using a randomisation test, flea species richness was repeatedly compared (1000 iterations), and the proportion of times that Individual A had more flea species than did Individual B, was recorded. This produced the P-value. Host species richness (the number of flea species found on a host) was tested in the same way.

All data manipulation, bootstrapping, randomisation, statistics and plotting were undertaken using R (R core Team 2013) and R packages network 1.9.0 (Carter et al. 2014a), sna 2.3.2 (Carter et al. 2014b) and plotrix (Lemon 2006).

Results

In total, 943 small mammals were captured in different habitats in the two districts comprising of 13 species of rodents (4 individuals of an unidentified species cfr Aethomys), several species of Crocidura and one elephant shrew (Petrodromus sp.; Fig. 1).

Mastomys natalensis dominated the captures (37.5\%) in fallow and cultivated land, whereas Lophuromys flavopunctatus and Praomys delectorum were most dominant in the moist forests $(15.6 \%$ and $14.1 \%$ ) respectively. These three species represented more than $66 \%$ of all rodents and shrews captured. Very few individuals of Rattus rattus (1.5\%) were captured, which was attributed to rodent-control campaigns and various hygienic measures in houses during the 2008-2011 plague epidemics in the two districts.

A diverse assemblage of fleas consisting of 26 species (Fig. 2) was collected from 576 rodents and shrews. About $61.1 \%$ of the small mammals were infested with a total load of 749 fleas. Seven species of fleas were the most prevalent, namely Ctenophthalmus calceatus spp., Ctenophthalmus sp., Dinopsyllus 
grypurus, D. lypusus, Pulex irritans, Xenopsylla brasiliensis and X. cheopis. Dinopsyllus grypurus, D. lypusus and X. brasiliensis represented more than 50\% of all collected fleas (Fig. 2).

The network graph shows clearly which hosts are connected with which fleas, and also which fleas are shared by host species in different and similar habitats (Fig. 3). Each host was given a different connection colour, so that it is easier to see how they are interconnected. Each point is a pie chart in itself, which indicates the habitats in which this species was found. So, for instance, if a point is $1 / 4$ blue and $3 / 4$ red, it was found in fields $25 \%$ of the times and in a domestic habitat $75 \%$ of the times.

There was a strong correlation (effect estimate $=2.7 \pm 0.5, \mathrm{r} 2=0.71, \mathrm{P}=0.0001$ ) between sample size (the log-transformed number of individuals of a host species) and species richness (the number of different flea species found on a host species), which is common for species richness data. This indicates that the sample size would determine the diversity of fleas on a particular group of hosts. If more Rattus individuals were trapped, it is likely that more flea species would have been found. Because of this correlation, we used randomisation (bootstrapping) and rarefaction methods for statistical testing.

The values of the rarefaction curves served as a basis for comparing fleas species richness among host species. Figures 4 and 5 are the rarefaction curves for the different host species for sample sizes 0-116 (Fig. 4) and 0-10 (Fig. 5).

Table 1 shows the results for P-values to compare all combinations of host species in relation to their flea species richness. For example, the P-value for the hypothesis that the number of fleas on Rhabdomys sp. was larger or equal to the number of fleas on M. natalensis is 0.24 , indicating that it is not rejected, and, therefore, the number of flea species is not assumed to be different. The P-value for the difference in the number of fleas between L. flavopunctatus and

P. delectorum was 1 , which means that L. flavopunctatus has significantly more flea species than has P. dlectorum (this was made clearer by reversing the 
hypothesis and, therefore, subtracting the P-value, 1 , from 1 , which gave a P-value of zero). These results were also clear from the rarefaction curves; the curve for L. flavopunctatus clearly lies higher than that of P. delectorum, indicating that it has more flea species.

Figures 6 and 7 show the rarefaction curves of different fleas species for sample sizes $0-100$ and $0-10$.

There were several flea species that were found on only one or two host species (ectoparasitic or free-living. Those that were found in a domestic environment, but not on a host, were C. felis $(n=4), T$. penetrans $(\mathrm{N}=3)$ and E. gallinacea $(n=2)$. Flea species found only on one host (L. flavopunctatus) were: C. evidens mbulu $(\mathrm{N}=6)$, X. lippa $(\mathrm{n}=1)$ and C. kemmelberg $(\mathrm{n}=2)$.

We carried out two-by-two comparisons of host species richness (Table 2). For each comparison, we calculated the P-values to test the hypothesis that the flea species in the first column have an equal or higher number of host species than do the flea species in the other columns. (e.g. C. felis vs $\mathrm{P}$. irritans $(\mathrm{P}=0.75)$; no evidence that $\mathrm{C}$. felis does not have the same or a higher number of host species than does $\mathrm{P}$. irritans; P. irritans vs $\mathrm{X}$. cheopis $(\mathrm{P}=0)$, so $\mathrm{P}$. irritans has significantly fewer host species than X. cheopis). The results in Table 2 can be matched with the rarefaction plots (Figs 6,7$)$ where the different flea species can be compared. To determine whether two species differ significantly, the exact P-value can be found in Table 2.

We were interested to know whether host sex, reproducive age (adult or subadult) or habitat had any influence on the abundance or species richness of fleas. There was slightly significant correlation between sex of rodent host and flea abundance (the number of fleas on an individual; effect estimate $=0.21 \pm 0.11$, $\chi 2=4.05$, d.f. $=1, \mathrm{P}=0.44)$, where flea abundance was higher on males. We also found that adults had more fleas than did subadults $(\mathrm{effect}$ estimate $=0.38$ $\pm 0.12, \chi^{2}=10.18$, d.f. $\left.=1, P=0.001\right)$. The number of different flea species that was found on an individual did not correlate with any measured variable (species, habitat, sex, breeding status), with individuals having a mean number of flea species of $1.3 \pm 0.1$ (maximum $=3$ different flea species on a host). 
There were significant differences in flea abundance between habitats $(\chi 2=57.692, \mathrm{Df}=7, \mathrm{P}<0.0001)$, where the lowest flea abundance was found in forest and the highest inside houses.

The current study contributes to understanding how fleas and rodent hosts are associated more specifically in a plague focus. We recorded 26 species of fleas in the plague outbreak foci in the Rift Valley, in comparison to the five species previously recorded (Msangi 1969; Kilonzo and Mhina 1983; Haule et al. 2013). In previous studies, Kilonzo and Mhina (1983) recorded seven rodent species in the plague outbreak areas in Mbulu District, compared with 13 species that were recorded in the current study. The present study has also provided evidence of a rich flea and rodent fauna in Mbulu and Karatu District plague foci. surveys of plague outbreaks in Mbulu District in northern Tanzania (Makundi et al. 2008). Some flea species (e.g. X. cheopis and X. brasiliensis) were found within the domestic environment on hosts such as R. rattus and on semi-domestic species such as A. niloticus and M. natalensis, and some wild rats (field hosts), e.g. L. flavopunctatus, Otomys sp. and Lemniscomys zebra. This shows that these fleas are able to bridge the domestic and sylvatic rodents in an enzootic or epizootic cycle of infections. Studies conducted in Uganda observed similar association; these flea species were branded 'bridging vectors' (Amatre et al. 2009).

The results show a complex of ecological relationships between fleas and rodents, which is not unique to this plague focus; in the western Unites States, Gage and Kosoy (2005) reported at least 18 rodent species and 27 or more flea species being involved in enzootic plague cycles. In our study, both host and habitat 
distribution of hosts in different habitats. Apart from two species (Mus sp. and Crocidura spp.), all rodent species hosted more than one flea species, with the highest flea species richness found on L. flavopunctatus. The total prevalence of fleas on small mammals hosts was $>60 \%$.

Environmental factors are important in determining the abundance of fleas in different habitats or geographical regions (Durden and Hinckle 2009). However, it has been demonstrated that flea species richness is positively correlated with rodent species richness (Thiagarajan et al. 2008). Studies in the Negev Desert, Israel, indicated that environmental parameters (e.g. humidity, temperature and materials of the host's nest) affect the flea assemblages of a host (Krasnov et al. 1997). The parasite -host relationship was also influenced by habitat type (Krasnov et al. 1998). However, the linkages between flea communities, host communities and habitat types appear to be manifested differently in different geographical regions (Laudisoit et al. 2009a). Therefore, under different habitats, the diversity and abundance of hosts will determine the dynamics of interaction between fleas and rodents.

The network graph showed the pattern of interaction between rodents and fleas, and the multiple relationships in particular habitats were obvious. This enables understanding the relationship between flea species and rodent hosts, which can be applied to predict potential pathways of disease transmissions (Eames and Keeling 2002; Drewe 2010), or potential coinfections, with particular flea-borne agents such as Y. pestis, Bartonella sp. or Rickettsia sp. Flea hosts were not uniformly distributed. L. flavopunctatus, P. delectorum and G. dolichurus were predominantly found in the forest, whereas A. niloticus and M. natalensis were captured solely in fallow land and farmland. However, some flea species were commonly associated with them. Indeed, the network analysis showed that flea-sharing among hosts is far wider than hitherto reported. For example, Amatre et al. (2009) observed flea-sharing only among few sylvatic rodents (A. niloticus and M. natalensis and with R. rattus and A. niloticus within the domestic environment).

Although, in our study, R. rattus and A. niloticus shared fleas, there is greater interaction and flea sharing among P. delectorum, M. natalensis, A. niloticus, L. flavopunctatus and L. zebra. Such interactions, especially involving several wild species of rodents, are necessary for maintenance of the enzootic cycle of 
plague (Wimsatt and Biggins 2009). The multiple networks shown in the current study suggest that an infectious host could easily infect other species through flea transfer, in particular because flea species are rarely host-specific and will feed on an available vertebrate host (Thomas 1996).

We found more fleas on adults than subadults, which is probably due to a typical positive correlation between weight/size and flea abundance $(\chi 2=4.1955$, d.f. $=1, P=0.040)$. We could not establish any significant correlation between size and the number of flea species on an individual, and neither between sex and flea abundance. However, the significant correlation between breeding status and flea abundance indicated that by including breeding status in the model, the effect of weight is at least partly corrected for. Also, abundance analyses should take weight into account, because that is a known important predictor of flea abundance.

Our study has some implications for plague persistence and transmission. Xenopsylla brasiliensis and D. lypusus showed similarities in relation to their host associations. Considering that these two species are confirmed plague vectors, it is plausible to suggest that they are important vectors in enzootic plague cycle in the Rift Valley districts in northern Tanzania. Xenopsylla brasiliensis is known for its high vector efficiency and to share a broad spectrum of rodent hosts, and therefore is implicated to be primarily involved in plague transmission to humans in the peri-domestic and domestic areas (Gage and Kosoy 2005).

The complex flea-host associations within different habitats (forest, cultivated crop areas, fallow and domestic areas) most probably enable Y. pestis to be transmitted easily among hosts in the enzootic cycle, and when bactaeremia of the carrier hosts become sufficiently high, spread to humans during epizootics. Several host-flea complexes have been reported in regions of enzootic and epizootic plague (e.g. Davis et al. 2002; Gage and Kosoy 2005; Amatre et al. 2009, Foley and Foley 2010). Studies of flea-host associations in plague foci in Uganda showed that rodent hosts in domestic and sylvatic areas shared some 
in Ituri, in the Democratic Republic of the Congo (A. Laudisoit, - personal observations). Our results also showed that these species of rodents are associated with wild and domestic rodents in the plague outbreak foci in the Rift Valley districts.

The results on how the flea species are connected to individual host species show that there are multiple channels for flea vectors to transmit $Y$. pestis among susceptible host species. It has been suggested that fleas living on hosts and in rodent burrows might significantly contribute to plague persistence (Wimsatt and Biggins 2009). Therefore, the presence of a large number of flea species in the study area that are connected to an equally large number of host species increases the potential for enzootic and epizootic cycles of plague to be maintained in the area. Studies in Uganda, for example, have suggested that when there are multiple vectors interacting with rodent species, it increases the persistence of plague in an active focus (Eisen et al. 2012).

Available evidence also indicates that the transmission of plague in sylvatic reservoirs is almost exclusively undertaken by fleabite (Bearden and Brubaker 2010), which suggests that the more complex the degree of association between hosts and fleas, the greater the potential for circulating the bacterium among a community of hosts. However, there are some plague-outbreak scenarios, such as in Madagascar, which is the most affected country in the world, where outbreaks involve only R. rattus and two flea species, namely, X. cheopis and Synopsyllus fonquerniei (Rahelinirina et al. 2010). The plague epidemics in Madagascar are not typical of established outbreak models in other parts of Africa. This is attributed to large populations of rodents and fleas, the latter being resistant to first-line insecticides, and is also exacerbated by anthropological factors, mainly increasing human population density, substandard housing infested with large numbers of rodents and fleas, and insufficient health-care industry (Winter 2014).

In previous studies in the Lushoto District, where plague outbreaks were recorded between 1980 and 2004 (Davis et al. 2006), differences in flea species diversity and abundance between plague-free and plague-endemic villages were reported, with higher diversity and abundance of fleas in the outbreak villages (Laudisoit et al. 2009b). Similar observations have been made in other foci in East Africa, for which high flea diversity was strongly associated with 
plague outbreaks (Eisen et al. 2012). It is, therefore, plausible to suggest that the high species richness of fleas and rodents in the Rift Valley districts contribute to maintenance and persistence of plague for which sporadic cases in humans have been recurring since 2008

Although the study showed a complex association and interaction between the potential vector and hosts, it did not shed any light on vector efficiency and reservoir potential of the hosts; laboratory studies accounting for level of parasitism in relation to immune status of the hosts are required to establish both.

Acknowledgement

We thank VLIR-UOS (Belgium) for funding through the Research Initiative Programme (RIP Project); Professor Herwig Leirs, University of Antwerp, for his support throughout implementation of the project; French flea taxonomist for flea identification and staff of the Pest Management Centre, Sokoine University, Morogoro, Tanzania, for field in trapping and processing of animals. The European Union funded Stoprats Project (Grant Contract ref. no. FED/2013/330-223), and sponsored the first (RHM) and second (AWM) authors of this paper to attend the 5th International Conference on Rodent Biology and Management in Zhengzhou, China, in August 2014, where the results of this study were presented.

References

<jrn>Amatre, G., Babi, N., Enscore, R. E., Ogen-Odoi, A., Atiku, L. A., Akol, A., Gage, K. L., and Eisen, R. J. (2009). Flea diversity and infestation prevalence on rodents in a plague-endemic region of Uganda. The American Journal of Tropical Medicine and Hygiene 81, 718-724. doi:10.4269/ajtmh.2009.09-0104</jrn $>$ 
<jrn>Bevins, S. N., Baroch, J. A., Nolte, D. L., Zhang, M., and Hongxuan, H. E. (2012). Yersinia pestis: examining wildlife plague surveillance in China and USA. Integrative Zoology 7, 99-109. doi:10.1111/j.1749-4877.2011.00277.x</jrn>

<eref $>$ Carter, T. B., Handcock, M. S., and Hunter, D. R. (2014a). 'Network: Classes for Relational Data. R Package Version 1.9.0.' (Irvine, CA.). University of Washington, USA. Available at http://statnet.org/</eref>. Accessed 10th October 2014.

<eref $>$ Carter, T. B., Handcock, M. S., and Hunter, D. R. (2014b). 'Network: Classes for Relational Analysis. R Package Version 2.3-2'. Available at http://CRAN.R-project.org/package=sna $</$ eref $>$ Accessed 10th October 2014.

$<$ jrn>Davis, R. M., Smith, R. T., Madon, M. B., and Sitko-Cleugh, E. (2002). Fleas, rodents and plague ecology at Chuchupate Campground, Ventura County, California. Journal of Vector Ecology 27, 107-127.</jrn $>$

$<$ jrn>Davis, S., Makundi, R. H., Machangu, R. S., and Leirs, H. (2006). Demographic and spatio-temporal variation in human plague at a persistent focus in Tanzania. Acta Tropica 100, 133-141. doi:10.1016/j.actatropica.2006.10.006</jrn>

$<$ jrn $>$ Drewe, J. A. (2010). Who infects whom? Social networks and tuberculosis transmission in wild meerkats. Proceedings Royal Society London B. Biology 277, 633-642.</jrn $>$

$<$ edb>Durden, L. A., and Hinckle, N. C. (2009). Fleas (Siphonaptera) In 'Medical and Veterinary Entomology'. 2nd edn. (Eds G. R. Mullen and L. A. Durden.) pp. 115-135. (Academic Press: New York.)</edb $>$

$<$ jrn $>$ Eames, K. T. D., and Keeling, M. J. (2002). Modelling dynamics and network heterogeneities in the spread of sexually transmitted diseases. Proceedings of the National Academy of Sciences, USA 99, 13330-13335. doi:10.1073/pnas.202244299</jrn> 
<jrn>Eisen, R. J., Borchert, J. N., Mpanga, J. T., Atiku, L. A., MacMillan, K., Boegler, K. A., Montenieri, J. A., Monaghan, A., and Gage, K. L. (2012). Flea diversity as an element for persistence of plague bacteria in an East African plague focus. PLoS One 7(4), e35598. doi:10.1371/journal.pone.0035598</jrn $>$

$<$ jrn $>$ Foley, P. and Foley, J. (2010). Modeling susceptible infective recovered dynamics and plague persistence in California rodent-flea communities. Vector-Borne and Zoonotic Diseases 10. doi:10.1089/vbz.2009.0048</jrn $>$

$<$ jrn>Gage, K. L., and Kosoy, M. Y. (2005). Natural history of plague: perspectives from more than a century of research. Annual Review of Entomology 50, 505-528. doi:10.1146/annurev.ento.50.071803.130337</jrn $>$

$<$ jrn>Haule, M., Lyamuya, E. E., Hang'ombe, B. M., Kilonzo, B. S., and Matee, M. I. (2013). Investigations of fleas as vectors in the transmission of plague during quiescent period in north-eastern Tanzania. Journal of Entomology and Nematology 5, 88-93. doi:10.5897/JEN2013.0083</jrn $>$

$<$ jrn>Kilonzo, B. S. (1976). A survey of rodents and their flea ectoparasites in north-eastern Tanzania. East African Journal of Medical Research 3, 117126. $</ \mathrm{jrn}>$

$<$ jrn>Kilonzo, B. S., and Mtoi, R. S. (1983). Entomological, bacteriological and serological observations after the 1977 plague outbreak in Mbulu District, Tanzania. East African Medical Journal 60, 91-97.</jrn>

Kilonzo, B.S. and Mhina, J.I.K. (1983). Observations on the current status of plague endemicity in the Western Usambara mountains, north-east Tanzania, Acta Tropica, 40, $365-373$.

<jrn>Kilonzo, B. S., Julius, M., Sabuni, C., and Mgode, G. (2005). The role of rodents and small carnivores in plague endemicity in Tanzania. Belgian Journal of Zoology 135(Suppl.), 119-125.</jrn> 
$<$ bok>Kingdon, J. (1974). 'The Kingdon Field Guide of African Mammals.' (A\&C Black Publishers.) </bok $>$

$<$ jrn $>$ Krasnov, B., Shenbrot, G. I., Medvedev, S., Vatschenok, V., and Khokhlova, I. (1997). Host-habitat relations as an important determinant of flea assemblages (Siphonaptera) on rodents in the Negev desert. Parasitology 114, 159-173. doi:10.1017/S0031182096008347</jrn $>$

<jrn>Krasnov, B., Shenbrot, G., Khokhlova, I., Medvedev, S., and Vatschenok, V. (1998). Habitat dependence of a parasite-host relationship: flea (Siphonaptera) assemblages in two gerbil species of the Negev desert. Journal of Medical Entomology 35, 303-313. doi:10.1093/jmedent/35.3.303</jrn>

Krasnov, B.R., Khokhlova, I.S. ( 2001). The effect of behavioural interactions on the transfer of fleas (Siphonaptera) between two rodent species. Journal of Vector Ecology 26, 181-190

$<$ bok>Krebs, C. J. (2009). 'Programs for Ecological Methodology. Version 7.1.' (Exeter Software.), Setauket, New York 11733-2870, USA. </bok>

$<$ jrn>Laudisoit, A., Neerinckx, S., Makundi, R. H., Leirs, H., and Krasnov, B. R. (2009a). Are local plague endemicity and ecological characteristics of vectors and reservoirs related? A case study in north-east Tanzania. Current Zoology 55, 200-211.</jrn>

<jrn>Laudisoit, A., Leirs, H., Makundi, R. H., and Krasnov, B. R. (2009b). Seasonal and habitat dependence of species composition of flea assemblages parasitic on small mammals in Tanzania. Integrative Zoology 4, 196-212. doi:10.1111/j.1749-4877.2009.00150.x</jrn>

<jrn>Laudisoit, A., Neerinckx, S., Makundi, R. H., Leirs, H., and Krasnov, B. (2010). Plague in Tanzania: from a host and vector perspective. Vector Borne and Zoonotic Diseases 10, 101.</jrn>

$<$ jrn>Leirs, H., Neerinckx, S., Laudisoit, A., and Makundi, R. H. (2010). Emergence and growth of plague foci in Africa. Vector Borne and Zoonotic Diseases (Larchmont, N.Y.) 10, 97.</jrn> 
$<$ jrn>Lemon, J. (2006) Plotrix: a package in the red light district of R. R-News 6, 8-12.</jrn $>$

<jrn>Makundi, R. H., and Kilonzo, B. S. (1994). Seasonal dynamics of rodent fleas and its implication on control strategies in Lushoto district, Tanzania.

Journal of Applied Entomology 118, 165-171. doi:10.1111/j.1439-0418.1994.tb00791.x</jrn>

$<$ edb $>$ Makundi, R. H., Kilonzo, B. S., and Massawe, A. W. (2003). Interaction between rodent species in agro-forestry habitats in the western Usambara mountains, northeast Tanzania, and its potential for plague transmission to humans. In 'Rats, Mice and People. Rodent Biology and Management'. (Eds G. R. Singleton, L. A. Hinds, C. J. Krebs and D. M. Spratt.) pp. 20-24. (Australian Centre for International Agricultural Research: Canberra.)</edb> $<$ jrn>Makundi, R. H., Massawe, A. W., and Mulungu, L. S. (2005). Rodent population fluctuations in three ecologically heterogeneous locations in northeast, central and south-west Tanzania. Belgian Journal of Zoology 135(Suppl.), 159-165.</jrn>

<jrn>Makundi, R. H., Massawe, A. W., Mulungu, L. S., Katakweba, A. S., Mbise, T. J., and Mgode, G. F. (2008). Potential mammalian reservoirs in a bubonic plague outbreak focus in Mbulu District, northern Tanzania, in 2007. Mammalia 72, 253-257. doi:10.1515/MAMM.2008.038</jrn>

$<$ jrn>Makundi, R. H., Massawe, A. W., Mulungu, L. S., and Katakweba, A. S. (2009). Diversity and population dynamics of rodents in farm-fallow mosaic fields in Central Tanzania. African Journal of Ecology 48, 313-320. doi:10.1111/j.1365-2028.2009.01109.x</jrn>

$<$ bok>Marshall, A. G. (1981). 'The Ecology of Ectoparasitic Insects.' (Academic Press: London.) $<$ /bok $>$

<jrn>McCauley, D. J., Salkeld, D. J., Young, H. S., Makundi, R. H., Dirzo, R., Eckerlin, R. P., Lambin, E. F., Gaffikin, L., Barry, M., and Helgen, K. M. (2015). Effects of land use on plague (Yersinia pestis) activity in rodents in Tanzania. The American Journal of Tropical Medicine and Hygiene doi:10.4269/ajtmh.14-0504.</jrn> 
$<$ jrn>Msangi, A. S. (1969). Entomological observations after the 1968 plague outbreak in Mbulu District, Tanzania. East African Medical Journal 46, 465470. $</ \mathrm{jrn}>$ doi:10.1016/j.pt.2010.05.008</jrn>

$<$ eref $>$ R CORE TEAM (2013). 'R: a Language and Environment for Statistical Computing.' (R Foundation for Statistical Computing: Vienna.) Available at http://www.R-project.org/.[Accessed [April 2013]</eref $>$

$<$ jrn>Rahelinirina, S., Duplantier, J. M., Ratovonjato, J., Ramilijaona, O., Ratsimba, M., and Rahalison, L. (2010). Study on the movement of Rattus rattus and evalauation of the plague dispersion in Madagascar. Vector Borne and Zoonotic Diseases 10, 77-84. doi:10.1089/vbz.2009.0019</jrn>

$<$ jrn>Thiagarajan, B., Cully, J. F., Jr, Loughin, T. M., Montenieri, J. A., and Gage, K. L. (2008). Geographic variation in rodent-flea relationships in the presence of black-tailed prairie dog colonies. Journal of Vector Ecology 33, 178-190. doi:10.3376/1081-1710(2008)33[178:GVIRRI]2.0.CO;2</jrn>

$<$ edb $>$ Thomas, R. E. (1996). Fleas and the agents they transmit. In 'The Biology of Disease Vectors'. (Eds B. J. Beaty and W. C. Marquardt.) pp. $146-159$. (University Press of Colorado: Niwot, CO.)</edb $>$

$<$ jrn>Wimsatt, J., and Biggins, D. E. (2009). A review of plague persistence with special emphasis on fleas. Journal of Vector Borne Diseases 46, 8599. $<$ jrn $>$

<eref $>$ Winter, L. (2014). 'Bubonic Plague Spread in Madagascar.' (IFLScience.) Available at http://www.iflscience.com/health-and-medicine/bubonicplague-outbreak-spreads-madagascar.[Accessed 23 March 2015]</eref $>$ 
<jrn>Ziwa, M. H., Matee, M. I., Kilonzo, B. S., and Hang'ombe, B. M. (2013). Evidence of Yersinia pestis DNA in rodents in plague outbreak foci in Mbulu and Karatu Districts, northern Tanzania. Tanzania Journal of Health Research 15, 1-8. doi:10.4314/thrb.v15i3.1</jrn $>$

Table 1. A two-by-two comparisons for all combinations of host species and flea species richness

\begin{tabular}{|c|c|c|c|c|c|c|c|c|c|c|c|}
\hline & Rhab & Mast & Arvi & Ratt & Gramm & Loph & Prao & Unid & Otom & Lemn & Aeth \\
\hline Domestic & 0.06 & 0.68 & 1.00 & 0.12 & 0.04 & 0.06 & 0.12 & 0.57 & 0.03 & 0.00 & 0.00 \\
\hline Rhabdomys sp. (Rhab) & & 0.24 & 0.76 & 0.06 & 0.35 & 0.07 & 0.15 & 1.00 & 0.00 & 0.00 & 0.00 \\
\hline Mastomys natalensis & & & & & & & & & & & \\
\hline (Mast) & & & 0.61 & 0.09 & 0.07 & 0.00 & 0.01 & 0.17 & 0.02 & 0.03 & 0.01 \\
\hline Arvicanthis sp. (Arvi) & & & & 0.00 & 0.00 & 0.00 & 0.00 & 0.05 & 0.00 & 0.00 & 0.00 \\
\hline Rattus rattus (Ratt) & & & & & 0.00 & 0.03 & 0.10 & 0.25 & 0.00 & 0.00 & 0.00 \\
\hline Grammomys & & & & & & 0.27 & 0.27 & 0.34 & 0.19 & 0.00 & 0.00 \\
\hline
\end{tabular}


(Gramm)

Lophuromys

sp.

(Loph)

$\begin{array}{lllll}1.00 & 0.33 & 0.12 & 0.32 & 0.04\end{array}$

Praomys delectorum

(Prao)

$\begin{array}{llll}0.21 & 0.09 & 0.02 & 0.03\end{array}$

Unidentified (Unid)

$\begin{array}{lll}0.00 & 0.00 \quad 0.00\end{array}$

Otomys sp. (Otom)

$0.05 \quad 0.00$

Lemniscomys zebra

(Lemn)

0.00

Aeth $=$ Aethomys

kaiseri

349 


\begin{tabular}{|c|c|c|c|c|c|c|c|c|c|c|c|c|c|c|c|c|c|c|c|c|c|c|c|}
\hline & $T p$ & $P i$ & $X c$ & $C c$ & Cca & $\mathrm{Dl}$ & Cs & $L d$ & $D g$ & $\boldsymbol{X b}$ & $\mathrm{Hc}$ & Eg & $\boldsymbol{L} \boldsymbol{b}$ & $\mathrm{Ni}$ & $X s$ & Ds & $X r$ & $C \boldsymbol{i}$ & Cem & $X I$ & $D r$ & $\boldsymbol{C k}$ & $L a$ \\
\hline Ctenocephalides felis & 1.00 & 0.75 & 0.09 & 1.00 & 0.01 & 0.23 & 0.12 & 0.00 & 0.06 & 0.20 & 0.11 & 1.00 & 0.01 & 0.00 & 0.00 & 0.00 & 0.00 & 0.00 & 1.00 & 1.00 & 0.00 & 1.00 & 0.00 \\
\hline Tunga penetrans $(T p)$ & & 0.86 & 0.37 & 1.00 & 0.18 & 0.49 & 0.39 & 0.50 & 0.33 & 0.49 & 0.38 & 1.00 & 0.20 & 0.16 & 0.00 & 0.33 & 0.22 & 0.00 & 1.00 & 1.00 & 0.00 & 1.00 & 0.00 \\
\hline Pulex irritans $(P i)$ & & & 0.00 & 1.00 & 0.00 & 0.03 & 0.00 & 0.24 & 0.00 & 0.10 & 0.00 & 1.00 & 0.00 & 0.00 & 0.13 & 0.18 & 0.00 & 0.12 & 1.00 & 1.00 & 0.12 & 1.00 & 0.14 \\
\hline Xenopsylla cheopis $(X c)$ & & & & 1.00 & 0.36 & 0.86 & 0.87 & 0.90 & 1.00 & 1.00 & 0.99 & 1.00 & 0.45 & 0.43 & 0.64 & 0.81 & 0.82 & 0.63 & 1.00 & 1.00 & 0.63 & 1.00 & 0.64 \\
\hline Ctenocephalides canis (Cc) & & & & & 1.00 & 1.00 & 1.00 & 1.00 & 1.00 & 1.00 & 1.00 & 1.00 & 1.00 & 1.00 & 1.00 & 1.00 & 1.00 & 1.00 & 1.00 & 1.00 & 1.00 & 1.00 & 1.00 \\
\hline Ctenophthalmus calceatus ( $\mathrm{Cca})$ & & & & & & 0.95 & 1.00 & 0.99 & 1.00 & 1.00 & 0.99 & 1.00 & 0.71 & 0.75 & 0.78 & 0.96 & 0.94 & 0.82 & 1.00 & 1.00 & 0.83 & 1.00 & 0.80 \\
\hline Dinopsyllus lypusus (Dl) & & & & & & & 0.87 & 0.76 & 1.00 & 1.00 & 0.66 & 1.00 & 0.21 & 0.22 & 0.47 & 0.64 & 0.45 & 0.46 & 1.00 & 1.00 & 0.50 & 1.00 & 0.48 \\
\hline Ctenophthalmus sp. (Cs) & & & & & & & & 0.86 & 1.00 & 1.00 & 0.85 & 1.00 & 0.30 & 0.31 & 0.58 & 0.75 & 0.65 & 0.59 & 1.00 & 1.00 & 0.61 & 1.00 & 0.58 \\
\hline Listropsylla dolosa (Ld) & & & & & & & & & 0.53 & 0.78 & 0.61 & 1.00 & 0.27 & 0.17 & 0.50 & 0.72 & 0.29 & 0.53 & 1.00 & 1.00 & 0.49 & 1.00 & 0.52 \\
\hline Dinopsyllus grypurus (Dg) & & & & & & & & & & 0.92 & 0.58 & 1.00 & 0.07 & 0.06 & 0.65 & 0.82 & 0.40 & 0.65 & 1.00 & 1.00 & 0.68 & 1.00 & 0.66 \\
\hline Xenopsylla brasiliensis $(\mathrm{Xb})$ & & & & & & & & & & & 0.31 & 1.00 & 0.02 & 0.02 & 0.50 & 0.69 & 0.21 & 0.52 & 1.00 & 1.00 & 0.49 & 1.00 & 0.49 \\
\hline Hypsophthalmus campestris $(H c)$ & & & & & & & & & & & & 1.00 & 0.02 & 0.02 & 0.50 & 0.69 & 0.21 & 0.52 & 1.00 & 1.00 & 0.49 & 1.00 & 0.49 \\
\hline Echidnophaga gallinacea $(E g)$ & & & & & & & & & & & & & 0.00 & 0.00 & 0.57 & 0.80 & 0.57 & 0.62 & 1.00 & 1.00 & 0.64 & 1.00 & 0.60 \\
\hline Listropsylla basilewisky (Lb) & & & & & & & & & & & & & 0.22 & 0.18 & 0.00 & 0.35 & 0.21 & 0.00 & 1.00 & 1.00 & 0.00 & 1.00 & 0.00 \\
\hline Nosopsyllus incisus $(\mathrm{Ni})$ & & & & & & & & & & & & & & 1.00 & 0.76 & 0.93 & 1.00 & 0.77 & 1.00 & 1.00 & 0.76 & 1.00 & 0.77 \\
\hline Xenopsylla sp. $(X s)$ & & & & & & & & & & & & & & & 0.83 & 0.97 & 1.00 & 0.80 & 1.00 & 1.00 & 0.81 & 1.00 & 0.81 \\
\hline Dinopsyllus sp. (Ds) & & & & & & & & & & & & & & & & 1.00 & 1.00 & 1.00 & 1.00 & 1.00 & 1.00 & 1.00 & 1.00 \\
\hline Xenopsylla robertsi $(\mathrm{Xr})$ & & & & & & & & & & & & & & & & & 0.58 & 0.67 & 1.00 & 1.00 & 0.67 & 1.00 & 0.68 \\
\hline Ctenophthalmus iraqwi (Ci) & & & & & & & & & & & & & & & & & & 0.79 & 1.00 & 1.00 & 0.79 & 1.00 & 0.78 \\
\hline Ctenophthalmus evidens mbulu (Cem) & & & & & & & & & & & & & & & & & & & 1.00 & 1.00 & 1.00 & 1.00 & 1.00 \\
\hline Xiphiopsylla lippa $(X l)$ & & & & & & & & & & & & & & & & & & & & 1.00 & 0.00 & 1.00 & 0.00 \\
\hline Dinopsylla robertsi $(\mathrm{Dr})$ & & & & & & & & & & & & & & & & & & & & & 1.00 & 1.00 & 1.00 \\
\hline Ctenophthalmus kemmelberg (Ck) & & & & & & & & & & & & & & & & & & & & & & 1.00 & 1.00 \\
\hline
\end{tabular}




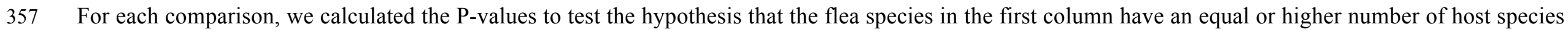
358 than the flea species in the other columns

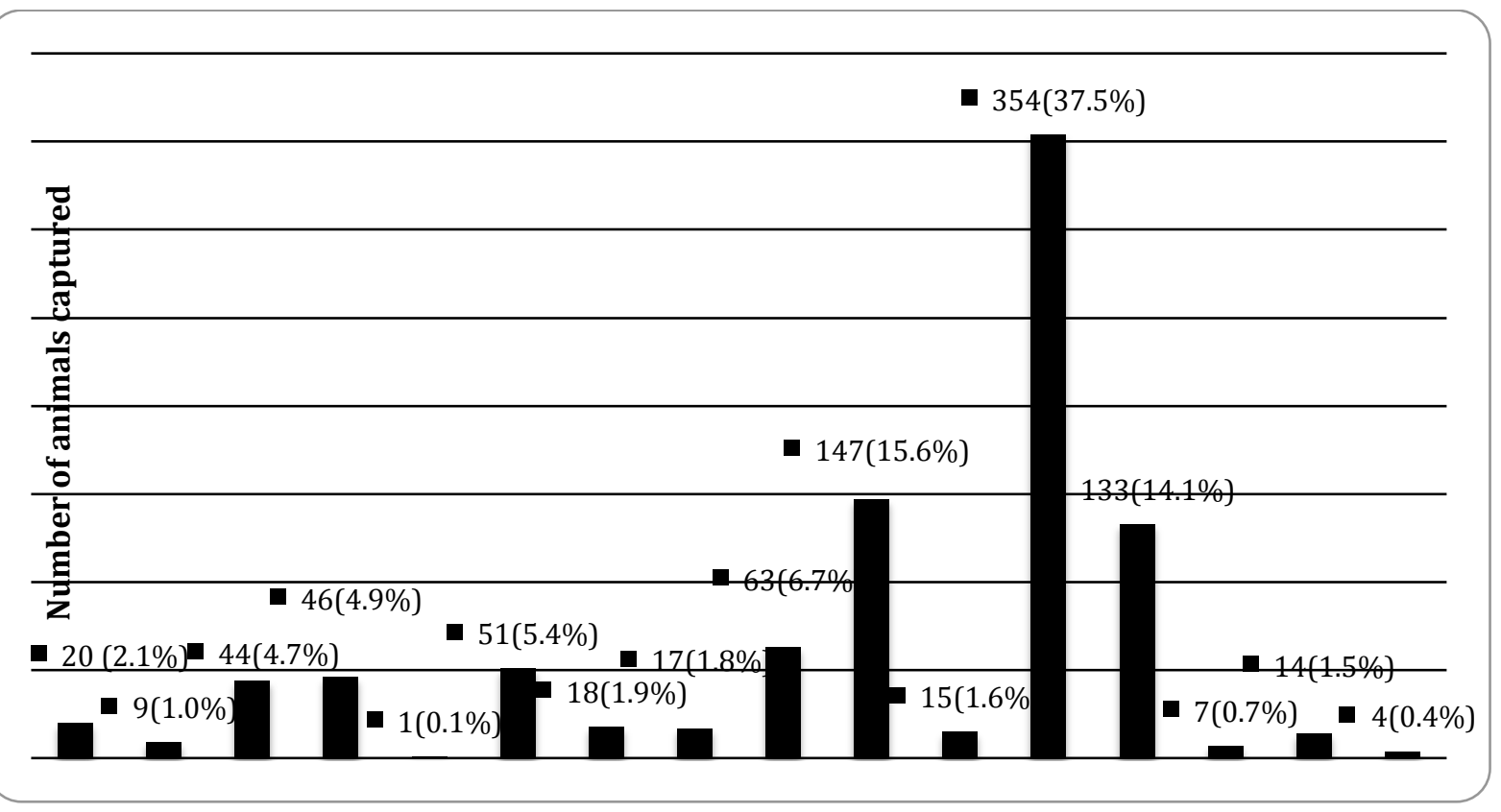

Fig. 1. Numbers and percentage of total of each species of rodents, Crocidura and elephant shrew (Petrodromus sp.) captured in the Rift Valley Districts of

Mbulu and Karatu, northern Tanzania. 


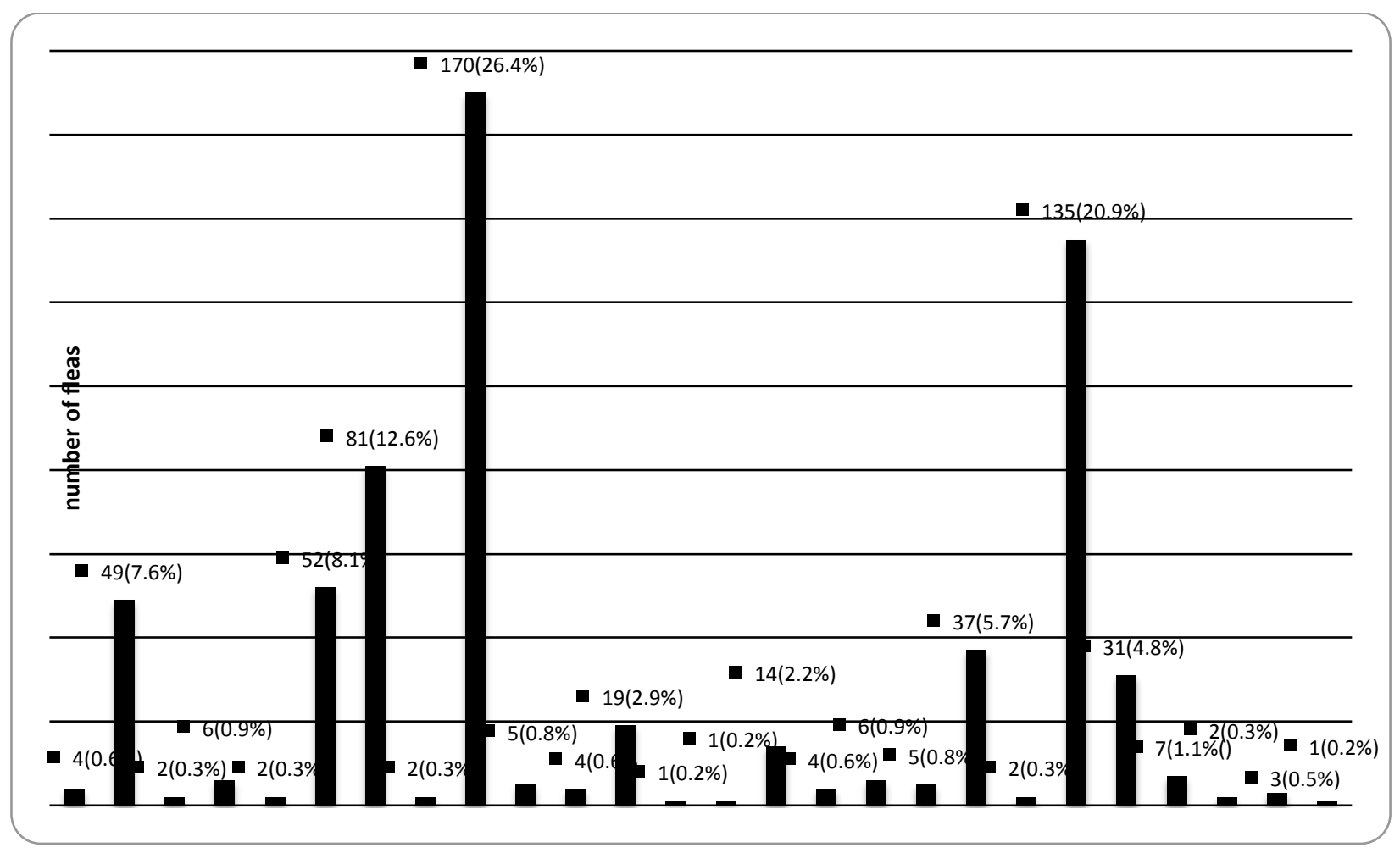

Fig. 2. Total number and percentage of total per species of fleas collected from rodent hosts in Karatu and Mbulu Districts, northern Tanzania. 
Association network fleas - hosts

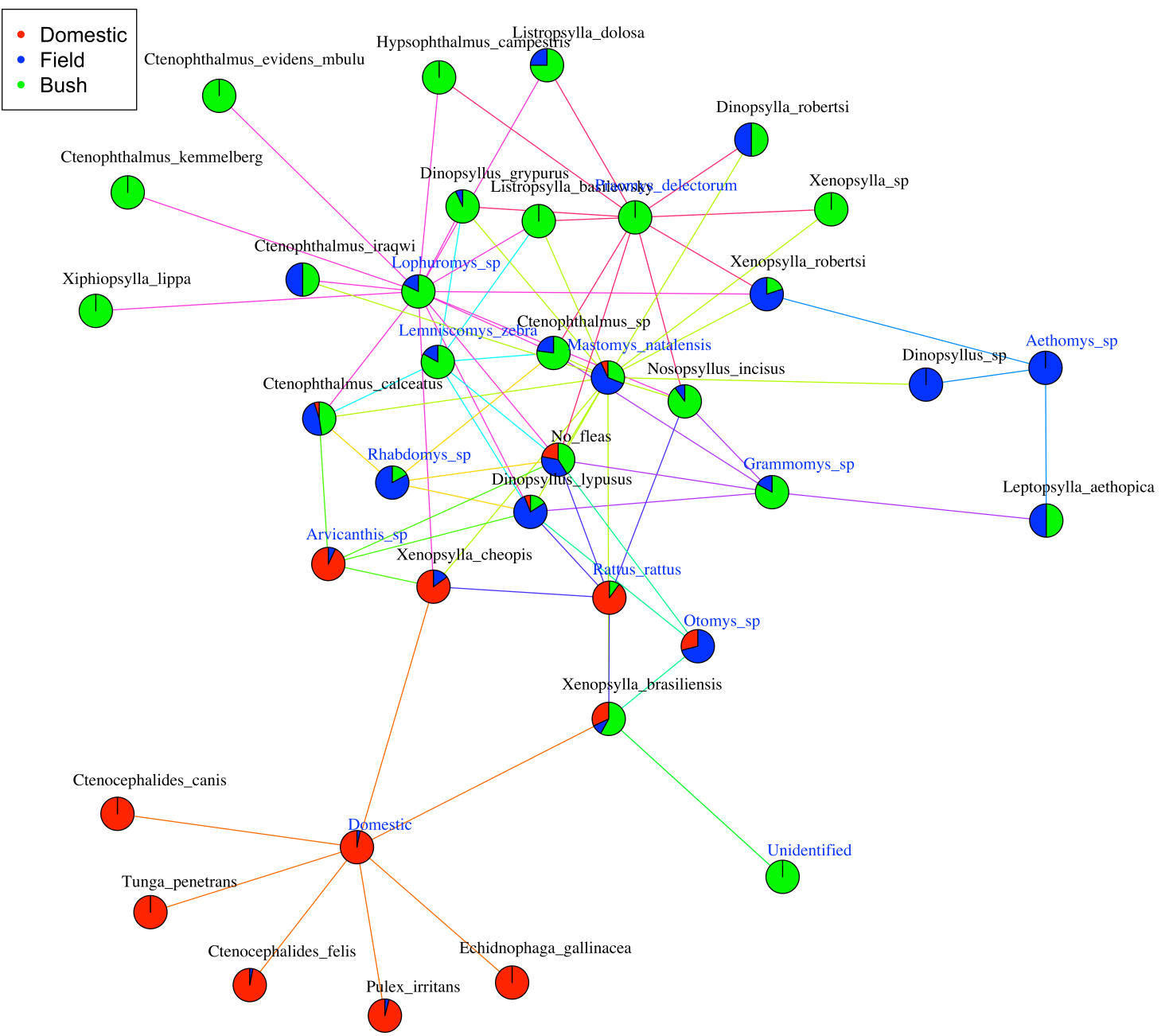


Fig. 3. Fleas, rodent and shrew host-association networks in different habitats in Mbulu district, northern Tanzania

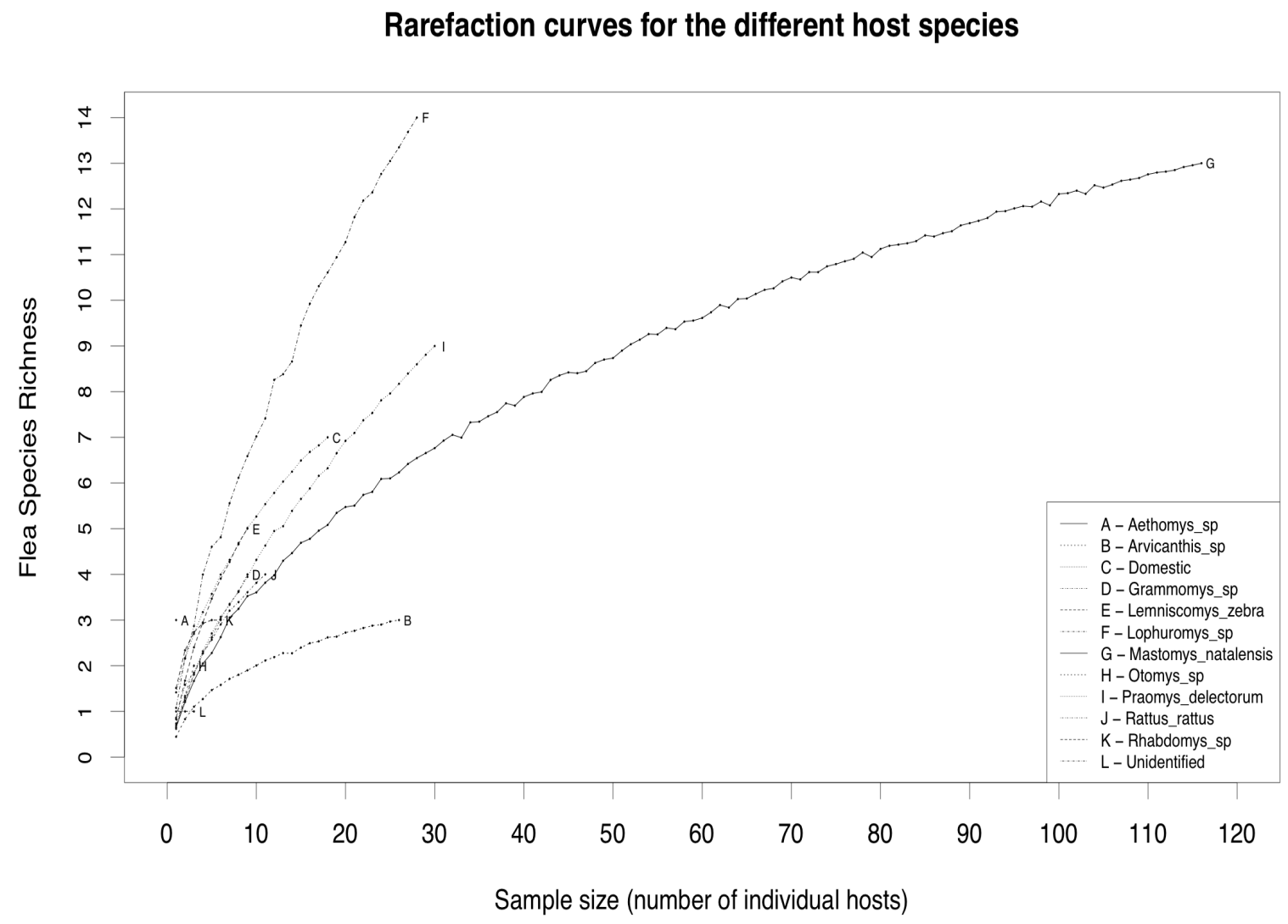

Fig. 4. Rarefaction curves for different host species (sample size 0-100). 
Rarefaction curves for the different host species

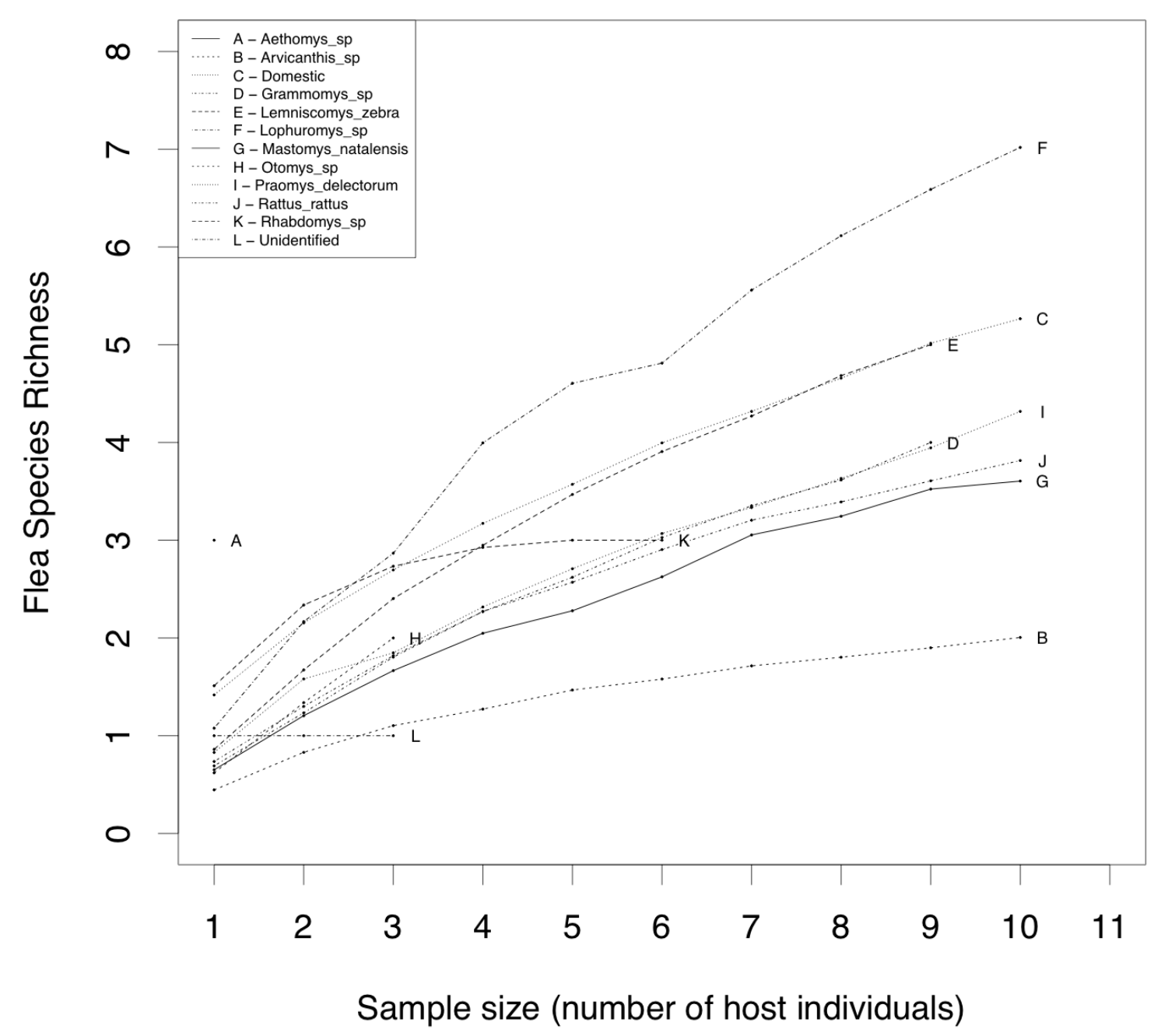


Fig. 5. Rarefaction curves for different host species (sample size 0-10)

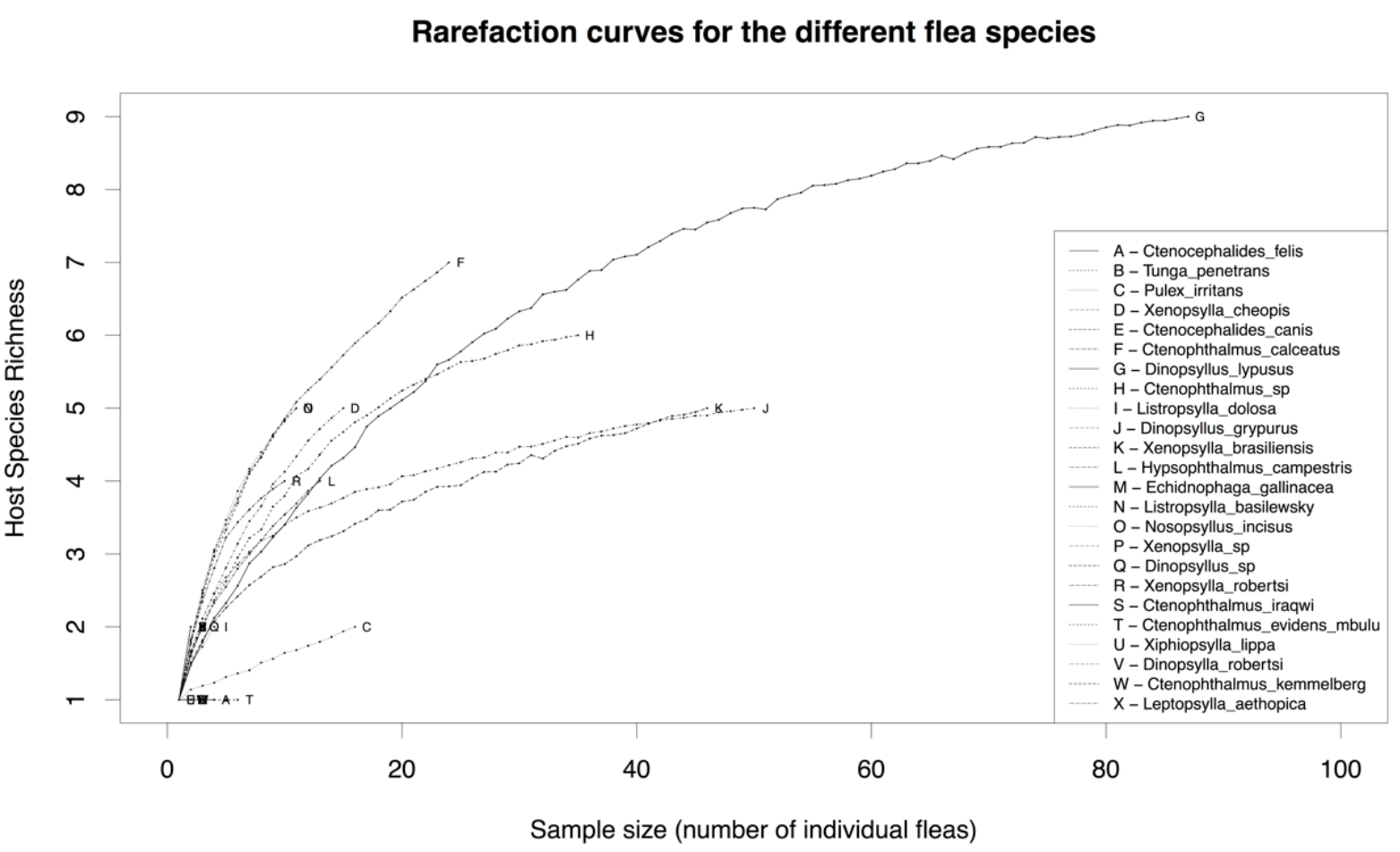

Fig. 6. Rarefaction curves of host species richness of different flea species (sample size 0-100). 


\section{Rarefaction curves for the different flea species}

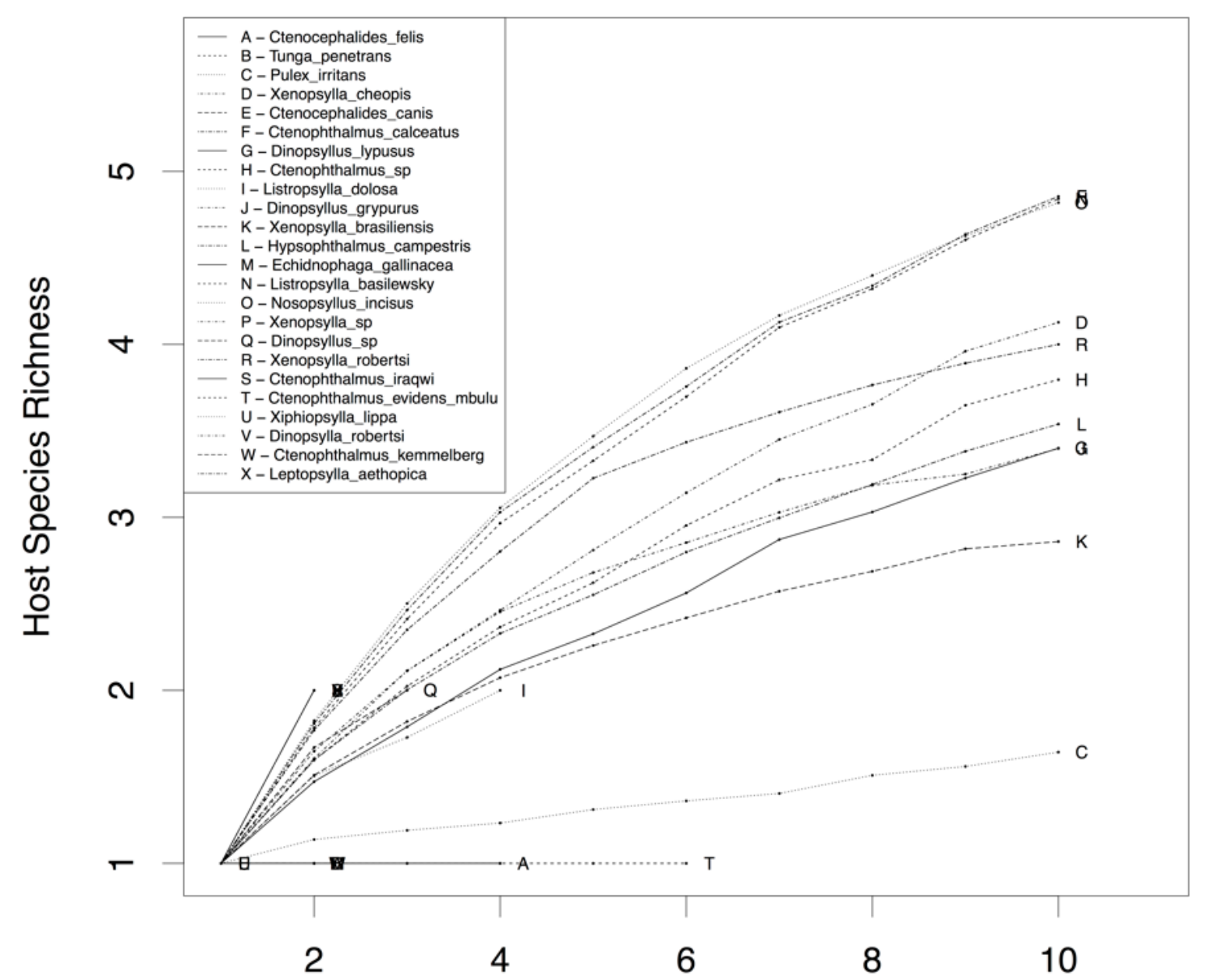

Sample size (number of flea individuals) 
Fig. 7. Rarefaction curves of host species richness of different flea species (sample size 0-10). 